\title{
Occasional Meeting
}

\section{Chestnuts, fats, and fibre}

\author{
TONY SMITH
}

Poor Professor Lewis, I thought, walking to St Thomas's Hospital through a London crowded with cyclists, rollerskaters, and pedestrians. After all the effort of arranging a meeting on the science and strategy of coronary heart disease prevention, he had found that both British Rail and the London Underground had chosen to go on strike. Inevitably many people who had wanted to attend could not get there; but in the end the atmosphere of pioneering determination pervading those who did arrive helped make the day stimulating and worth while.

The conference heard a lot of information on many aspects of a much discussed, debated, and dissected problem. Some chestnuts were trotted out yet again, but most of the emphasis was on new material or nuances. Firstly, and most important, at last Britain has joined the group of nations with a declining rate of coronary heart disease. Time and again in the past ten years epidemiologists have shown charts of a falling mortality from coronary heart disease in Australia and the United States while the rates in Britain have remained constant. Dr R Heller has now analysed data up to 1979-80 and found a drop since the mid-decade in deaths from coronary heart disease in both men and women, most appreciable in the age range 35-44 but also evident in the 45-54 year olds. Little change has occurred in the over $55 \mathrm{~s}$. These changes in mortality had been expected, for consumption rates of both cigarettes and of fat have been dropping since the mid-1960s, but the downturn was clearly welcome news to the health educators present.

\section{Beliefs challenged}

Much of the discussion was centred on the results of largescale controlled trials. Some of the results challenged accepted beliefs. In particular, Professor Geoffrey Rose and other speakers from the United States and Europe seemed agreed that in population studies dietary changes had the most important effect on the incidence of coronary heart disease-much more than did changes in smoking. The relative freedom of the Japanese from coronary heart disease despite their very heavy smoking was good evidence that tobacco was no great threat to an otherwise healthy heart.

Despite all the subtleties of low and high density lipoprotein fractions, in practical terms the key to lowering mortality rates from coronary heart disease seemed to lie in a diet that lowered the serum concentration of cholesterol. A $15 \%$ or so

British Medical Journal, London WC1H 9JR

TONY SMITH, MA, BM, deputy editor reduction (a reasonable target) could be achieved either by cutting down total fat intake substantially or by replacing some of the intake of saturated fat by polyunsaturated fat. Pectin and fibre could help; but the lipid-lowering action of a high fibre diet seemed to be due to the near impossibility of eating much fat with such a diet. In fact, a study on Trappist monks had shown that when the rest of the diet remained unchanged adding fibre led to a rise in their serum cholesterol concentrations.

What about the over-65s, asked Sir Cyril Clarke? All this talk about risk factors was based on populations between 35 and 65. Could senior citizens gorge themselves on fat and alcohol and smoke like chimneys with impunity? No one was very keen to answer. In general, old people showed fewer benefits from intervention studies-possibly because they were more stubborn and possibly because their disease was less modifiable. Sixty-five year olds were in good or bad health as a result of their life style in the previous 30 odd years; radical change was unlikely at that stage. Few clinicians, however, would want to persuade a reluctant pensioner to accept treatment for mild hypertension or to switch to a diet that made her miserable.

\section{Drawbacks of "prudent" diet}

Might a diet designed to lower the serum cholesterol concentration be positively harmful ? Professor Barry Lewis looked at the reports suggesting that lowering the cholesterol might increase the risks of cancer of the colon (and possibly elsewhere) and argued that these results had been misinterpreted. Closer examination showed that the determining factor was beta-carotene, the vitamin A precursor thought to protect against cancer. In populations in which cholesterol and beta-carotene are closely associated a rise in cholesterol might seem to protect against cancer, but the effect would be due to the accompanying rise in beta-carotene. Furthermore in Japan, where serum cholesterol concentrations had risen as fat consumption had increased, cancers of the breast, colon, and pancreas had become more not less frequent.

\section{Smoking}

Dr Michael Russell had some provocative views on health education and smoking. History showed, he claimed, that many people would not stop smoking despite threats of fines, imprisonment, or even death (drawing, quartering, and beheading in Turkey). Nor could cigarettes usefully be modified until epidemiologists could say more about the relative dangers of tar, carbonmonoxide, and nicotine. Nicotine was the addictive drug, and addicts could be helped to stop by giving them 
nicotine chewing gum. Snuff might provide a medically acceptable alternative to smoking - or possibly acidicts could be switched to a liquid preparation of pure nicotine for nasal inhalation.

\section{Prevention}

Where did this leave the health educators? As Professor Rose observed, it was unrealistic to take a group within a country and expect its members to behave differently from the country as a whole. The progressive decline in mortality from heart disease in the United States had affected men and women, blacks and whites, and had been due, he believed, to national changes in eating habits.

Permanent change had to have its origins in the grass roots of a community, said Professor J W Farquhar of Stanford University. His health programmes relied on co-operation from adult education classes, pensioners' organisations, and a whole range of voluntary and community groupings.

In the end, therefore, the British health educators were left a little cheered that at last Britain had joined the nations with declining mortality from coronary heart disease, but they face a mammoth task. The British can expect the same low mortality rates as the French, Italians, and Greeks when they eat the same sorts of food. So how are the insular, arrogant British to be convinced that foreigners know best?

\title{
Lesson of the Week
}

\section{Treatment of severe tetany due to hyperventilation during labour with a mixture of nitrous oxide, oxygen, and carbon dioxide}

\author{
V P ARGENT
}

The direct result of hyperventilation that accompanies painful uterine contractions is a definite and progressive reduction in maternal arterial carbon dioxide tension $\left(\mathrm{PCO}_{2}\right) .{ }^{1}$ This is often exacerbated by fear and anxiety. The severe tetany that may result from appreciable respiratory alkalosis leads to painful spasms of the voluntary muscles. This adds to the pain of uterine contractions and leads to further hyperventilation. The $\mathrm{PCO}_{2}$ tension in pregnancy is already low, the mean being $4 \cdot 1$ $\mathrm{kPa}(30.8 \mathrm{~mm} \mathrm{Hg})$, owing to an increased minute volume, and in labour severe hyperventilation may lead to a further drop to 2 or $3 \mathrm{kPa}(15-22 \mathrm{~mm} \mathrm{Hg}) .{ }^{2}$ There is experimental evidence that this degree of hypocapnia may lead to fetal hypoxia and acidosis. ${ }^{3}$ Furthermore, increasing the concentration of maternal inspired oxygen consistently increases fetal oxygen tension $\left(\mathrm{Po}_{2}\right) .{ }^{4}$

Severe tetany due to hyperventilation in labour should therefore be treated by a method that provides a high inspired carbon dioxide concentration, a high inspired oxygen concentration, and also analgesia.

\section{Case report}

The patient was 26 years old and in her fourth pregnancy. She had had a therapeutic termination followed by a full term normal delivery in 1975 and a full term assisted breech delivery in 1980. In the current pregnancy she went into spontaneous labour at term and, after six hours in the first stage, the cervix was dilated $5 \mathrm{~cm}$. The membranes ruptured and she experienced extremely painful uterine contractions despite having been given

Freedom Fields Hospital, Plymouth PL4 7JJ

V P ARGENT, DRCOG, FFARCS, registrar in obstetrics and gynaecology
Severe hyperventilation during labour should be treated by using an anaesthetic machine that delivers high oxygen and carbon dioxide concentrations as well as analgesia

$100 \mathrm{mg}$ intramuscular pethidine one hour before. She was hyperventilating and her midwife was unable to persuade her to breathe less deeply. She developed tingling in the finger tips followed by severe tetanic spasms of the arms and legs.

There was no fetal distress apparent on the cardiotacograph trace obtained via a scalp electrode. The midwife instructed the patient to rebreathe into a paper bag, but the patient was uncooperative and it was impossible to obtain a good bag-to-mouth seal. During contractions the paper bag was removed and the patient encouraged to breathe $50 \%$ oxygen and $50 \%$ nitrous oxide via an Entonox apparatus. After 25 minutes she was unmanageable and a doctor was summoned. Ten $\mathrm{ml}$ of $10 \%$ calcium gluconate was given intravenously with no effect. Ten minutes later she still had severe tetany with rigid painful carpopedal spasm and flexor spasms of the arms and legs, and the pain of the spasms was greater than that of the uterine contractions. Her respirations were jerky and speech was difficult. It was impossible for her to rebreathe into a paper bag. A rubber face mask from an anaesthetic machine was held on her face and fresh gas was delivered via a Magill circuit connected to a Boyles anaesthetic machine. The rotameters were set at nitrous oxide 3 litres, oxygen 3 litres, and carbon dioxide 2 litres, giving a total flow of 8 litres per minute. The patient's minute ventilation was higher than the fresh gas flow so that the actual inspired $\mathrm{CO}_{2}$ would have been slightly higher than $25 \%$ because of rebreathing from the Magill circuit.

There was a dramatic response within three minutes, and she 